\title{
Review
}

\section{Role of biomarkers for the diagnosis of prion diseases}

Miren Altuna1,2*, Iñigo Ruiz, María Victoria Zelaya3 , Maite Mendioroz ${ }^{4,5}$

${ }^{1}$ Sant Pau Memory Unit, Hospital de la Santa Creu i Sant Pau - Biomedical Research Institute Sant Pau - Universitat Autònoma de Barcelona, 08041 Barcelona, Spain.

${ }^{2}$ Centre of Biomedical Investigation Network for Neurodegenerative Diseases (CIBERNED), Madrid, Spain.

${ }^{3}$ Department of Pathological Anatomy. Hospital Universitario de Navarra. Pamplona, Spain.

${ }^{4}$ Department of Neurology. Hospital Universitario de Navarra. Pamplona, Spain.

${ }^{5}$ Neuroepigenetics Laboratory-Navarrabiomed, Hospital Universitario de Navarra, Universidad Pública de Navarra (UPNA), IdiSNA (Navarra Institute for Health Research), Pamplona, Navarra, Spain.

* corresponding author (Miren Altuna): mialaz@gmail.com. Sant Pau Memory Unit, Hospital de la Santa Creu i Sant Pau - Biomedical Research Institute Sant Pau - Universitat Autònoma de Barcelona, 08041 Barcelona, Spain. Tel.: +34-935-56-59-86; Fax: +34-935-56$56-02$.

Abstract: Prion diseases are progressive and irreversible neurodegenerative disorders with a low incidence (1.5-2 cases per million per year). Genetic (10-15\%), acquired (anecdotal) and sporadic (85\%) forms of the disease have been described. The clinical spectrum of prion diseases is very varied, although the most common symptoms are rapidly progressive dementia, cerebellar ataxia and myoclonus. Mean life expectancy from the onset of symptoms is 6 months. There are currently diagnostic criteria based on clinical phenotype as well as neuroimaging biomarkers (magnetic resonance imaging), neurophysiological tests (electroencephalogram and polysomnogram) and cerebrospinal fluid biomarkers (14-3-3 protein and real-time quaking induced conversion (RT-QuIC)). The sensitivity and specificity of some of these tests (electroencephalogram and 14-3-3 protein) is under debate and the applicability of other tests such as RT-QuIC is not universal. However, the usefulness of these biomarkers beyond the most frequent prion disease, sporadic Creutzfeldt-Jakob disease, remains unclear. Therefore, research is being carried out on new, more efficient cerebrospinal fluid biomarkers (total tau, ratio total tau/phosphorylated tau and neurofilament light chain) and potential blood biomarkers (neurofilament light chain among others) to try to universalize access to early diagnosis in the case of prion diseases.

Keywords: prion disease, biomarkers, diagnosis, dementia, neurodegeneration. 


\section{Introduction:}

Prion diseases, also known as transmissible spongiform encephalopathies, are rapidly progressive and irremediably fatal neurodegenerative disorders. The average life expectancy is 6 months, but great variability in the duration of the clinical course of the disease has been described, lasting from weeks to years [1-3]. The cause is the aggregation of a misfolded protein, scrapie (PrPSc), which propagates and aggregates in the brain tissue. PrPsc is neurotoxic and its accumulation leads to synaptic degeneration and disorganization, which induces neuronal loss and spongiform changes. Indeed, a reduction of over $30 \%$ in the relative synaptic index has been reported in prion disease-affected brains $[1,3,4]$.

Prion diseases are classified into sporadic (85\%), genetic (10-15\%), due to mutations in the prion protein gene (PRNP), and acquired (exceptional) forms (Figure 1). Prion diseases show a huge variety of cognitive, motor and neuropsychiatric symptoms. Almost $90 \%$ of the sporadic cases are due to sporadic Creutzfeldt-Jakob disease (sCJD) with an incidence close to 1.5-2 cases per million persons-year [3]. In addition to familial Creutzfeldt-Jakob disease, genetic causes include familial fatal insomnia (FFI) (of which there is also a very rare sporadic form), GerstmannStraüssler-Sheincker syndrome (GSS) and Huntington disease-like 1 (HDL1) [5,6]. In turn, in 1996, the variant Creutzfeldt-Jakob (vCJD), a zoonotic prion disease acquired by consumption of cattle contaminated by bovine spongiform encephalopathy, was described for the first time in the United Kingdom [7,8]. Fortunately, sanitary measures and food chain regulation have contributed to the near disappearance of the vCJD [7]. But regardless of the type of prionopathy, early diagnosis is a challenge due to the great phenotypic variability, with the most frequent symptoms being rapidly progressive dementia, cerebellar ataxia and myoclonus [3].

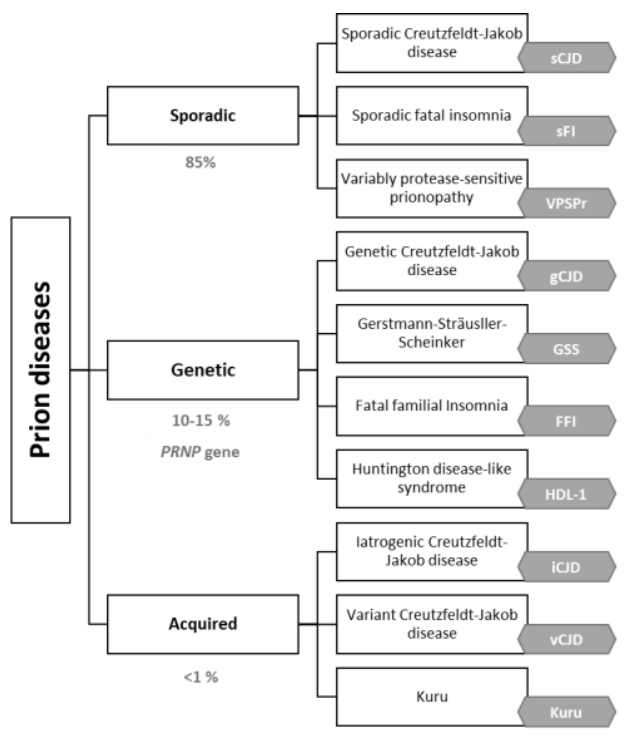

Figure 1: Prion diseases classification.

Currently, the definitive diagnosis of prion diseases requires postmortem anatomopathological examination or brain biopsy, which is not feasible in clinical practice $[1,3]$ (Table 1$)$. The 
postmortem neuropathological study is also necessary to classify cases into the different subtypes of sCJD. Different clinicopathological subtypes of SCJD, defined by methionine/valine polymorphism at codon 129 of the PRNP gene and the type (based on the size of proteaseresistant fragments) of PrPSc accumulated in the brain, have been described [3,9] (Table 2). The molecular subtype of sCJD is an important prognostic marker for patient survival [3].

\begin{tabular}{|c|c|c|c|c|c|c|c|}
\hline \multirow{2}{*}{\multicolumn{2}{|c|}{ sCJD }} & \multicolumn{3}{|c|}{ PROBABLE DISEASE } & \multicolumn{3}{|c|}{ DEFINITIVE DISEASE } \\
\hline & & $\begin{array}{l}\text { Rapidly progressive cognitive impairment AND } \\
\text { typical EEG (generalized periodic complexes) OR } \\
\text { typical MRI (high signal in caudate/putamen or at } \\
\text { least two cortical regions either on DWI or FLAIR) OR } \\
\text { positive 14-3-3 AND 2 of the following: } \\
\text { - Myoclonus } \\
\text { - Visual or cerebellar problems } \\
\text { - Pyramidal or extrapyramidal features } \\
\text { - Akinetic mutism }\end{array}$ & OR & $\begin{array}{l}\text { Progressive neurological syndrome AND } \\
\text { positive RT-QuIC in CSF or other tissues. }\end{array}$ & \multicolumn{3}{|c|}{$\begin{array}{l}\text { Progressive neurological syndrome AND neuropathologically OP } \\
\text { immunocytochemically OR biochemically confirmed. }\end{array}$} \\
\hline & $\mathrm{gCJD}$ & $\begin{array}{l}\text { Progressive neuropsychiatric disorder AND definite } \\
\text { or probable CID in } 1^{\text {st }} \text { degree relative }\end{array}$ & OR & $\begin{array}{l}\text { Progressive neuropsychiatric disorder } \\
\text { AND pathogenic PRNP mutation }\end{array}$ & $\begin{array}{l}\text { Definitive CID AND definitive } \\
\text { or probable CID in } 1^{\text {tt }} \text { degree } \\
\text { relative }\end{array}$ & OR & $\begin{array}{l}\text { Definitive CJD AND pathogenic } \\
\text { PRNP mutation }\end{array}$ \\
\hline & vCJD & \multicolumn{3}{|c|}{$\begin{array}{l}\text { Progressive neuropsychiatric disorder with duration of illness }>6 \text { months, no history of potential iatrogenic } \\
\text { exposure, no evidence of gCID and no alternative diagnosis suggested by routine investigations AND positive } \\
\text { tonsil biopsy OR bilateral pulvinar high signal on MRI AND not typical appearance of SCJD on EEG in the early } \\
\text { stages AND } 4 \text { of the following: } \\
\text { - Early psychiatric symptoms (depression, anxiety, apathy, withdrawal, delusions) } \\
\text { - Persistent painful sensory symptoms (frank pain or dysaesthesia) } \\
\text { - Ataxia } \\
\text { - Myoclonus, chorea or dystonia } \\
\text { - Dementia }\end{array}$} & \multicolumn{3}{|c|}{$\begin{array}{l}\text { Progressive neuropsychiatric disorder AND neuropathological } \\
\text { confirmation (spongiform change and extensive PrP deposition with } \\
\text { florid plaques throughout the cerebrum and cerebellum) }\end{array}$} \\
\hline & iCJD & \multicolumn{3}{|c|}{$\begin{array}{l}\text { Progressive cerebellar syndrome in a recipient of human cadaveric-derived pituitary hormone OR } \\
\text { sporadicCJD with a recognized exposure risk }\end{array}$} & \multicolumn{3}{|c|}{$\begin{array}{l}\text { Progressive cerebellar syndrome or sporadic CID with a recognized } \\
\text { exposure risk AND neuropathological confirmation }\end{array}$} \\
\hline \multicolumn{2}{|c|}{ VPSPr } & $\begin{array}{l}\text { Cognitive impairment and/or two of the following: } \\
\text { - Psychiatric symptoms } \\
\text { - Parkinsonism } \\
\text { - Aphasia } \\
\text { - Ataxia } \\
\text { - Myoclonus }\end{array}$ & AND & $\begin{array}{l}\text { Less than } 8 \text { years duration AND absence of } \\
\text { alternative etiology or phenotype } \\
\text { divergence from } \\
\text { neurodegenerative dementias }\end{array}$ & $\begin{array}{l}\text { Progressive neurological } \\
\text { confirmation }\end{array}$ & syndro & ne AND neuropathological \\
\hline \multicolumn{2}{|c|}{$\mathrm{sFI}$ and $\mathrm{FFI}$} & $\begin{array}{l}\text { Organic sleep disturbances. If not yet clinically } \\
\text { apparent, a polysomnography has to be performed. } \\
\text { At least two of the following: } \\
\text { - Psychiatric symptoms (visual hallucinations, } \\
\text { personality changes, depression, anxiety, } \\
\text { aggressiveness, disinhibition, listlessness) } \\
\text { - Ataxia } \\
\text { - Visual symptoms } \\
\text { - Myoclonus } \\
\text { - Cognitive/mnesic deficits }\end{array}$ & AND & $\begin{array}{l}\text { One of the following: } \\
\text { - Loss of }>10 \text { kg during the last } 6 \text { months } \\
\text { - Vegetative signs (hyperhidrosis, newly } \\
\text { diagnosed arterial hypertonia, } \\
\text { tachycardia, constipation, hyperthermia) } \\
\text { - Husky voice }\end{array}$ & $\begin{array}{l}\text { Progressive neurological } \\
\text { confirmation }\end{array}$ & syndro & ne AND neuropathological \\
\hline \multicolumn{2}{|c|}{ GSS } & \multicolumn{3}{|c|}{$\begin{array}{l}\text { Progressive cerebellar syndrome, cognitive impairment and/or sensory symptoms AND pathogenic PRNP } \\
\text { mutation }\end{array}$} & \multicolumn{3}{|c|}{$\begin{array}{l}\text { Progressive neurological syndrome AND neuropathological } \\
\text { confirmation (amyloid deposits immunoreactive for PrP are the } \\
\text { morphological hallmark of GSS) }\end{array}$} \\
\hline \multicolumn{2}{|c|}{ HDL-1 } & \multicolumn{3}{|c|}{$\begin{array}{l}\text { Abnormal involuntary movements, coordination difficulty, dementia, personality changes and psychiatric } \\
\text { symptoms AND pathogenic PRNP mutation }\end{array}$} & \multicolumn{3}{|c|}{ Kuru and multicentric plaques that stain with anti-prion antibodies } \\
\hline
\end{tabular}

Table 1: Diagnostic criteria for probable and definite categories of prion diseases. EEG: electroencephalogram; MRI: magnetic resonance imaging; CSF: cerebrospinal fluid. 


\begin{tabular}{|c|c|c|c|c|c|}
\hline \multirow[t]{2}{*}{ CLASIFFICATION } & \multirow[t]{2}{*}{ FREQUENCY } & \multicolumn{3}{|c|}{ FEATURES } & \multirow[t]{2}{*}{ PATHOLOGY AND IMMUNOCHEMISTRY } \\
\hline & & Clinical features & $\begin{array}{l}\text { Codon } \\
\text { genotype }\end{array}$ & $\begin{array}{l}\text { Expected } \\
\text { survival }\end{array}$ & \\
\hline PrPsc type 1 & $14 \%$ & Myoclonic variant & $100 \% \mathrm{MM}$ & 1-5 months & $\begin{array}{l}\text { Focal and confluent spongiform change predominant in occipital cortex, with synaptic } \\
\text { and focal perivacuolar deposits and without plaques. }\end{array}$ \\
\hline PrPsc type 2 & $48 \%$ & $\begin{array}{l}\text { Ataxic variant (VV, MV) and } \\
\text { dementia with long } \\
\text { duration (MM) }\end{array}$ & \begin{tabular}{l|}
$70 \%$ MM, \\
$15 \% \mathrm{MV}$ and \\
$15 \% \mathrm{VV}$.
\end{tabular} & 1-17 months & $\begin{array}{l}\text { Variable spongiform change predominant in frontal and occipital cortex, } \\
\text { parahippocampal gyrus, basal ganglia and cerebellum. Variable in Ammon's horn. } \\
\text { Synaptic and perivacuolar deposits in cortex, basal ganglia and cerebellum. Plaque-like } \\
\text { and band-like deposits can be found. }\end{array}$ \\
\hline PrPSc type 3 & $12 \%$ & $\begin{array}{l}\text { latrogenic and sporadic } \\
\text { cases. }\end{array}$ & $\begin{array}{l}45 \% \mathrm{MV} \text { and } \\
55 \% \mathrm{VV} \text {. }\end{array}$ & $2-21$ months & $\begin{array}{l}\text { Spongiform change in cerebral cortex, cerebellum and basal ganglia. Plaque-like deposits } \\
\text { and Kuru-type plaques can be found as hallmark. }\end{array}$ \\
\hline PrPSc type 4 & $25 \%$ & $\begin{array}{l}\text { All VCID with progressive } \\
\text { neuropsychiatric disorder }\end{array}$ & $100 \% \mathrm{MM}$ & 9-29 months & $\begin{array}{l}\text { Plaques and severe spongiform changes in basal ganglia and thalamic gliosis. Cluster } \\
\text { plaques in cerebral and cerebellar cortex and synaptic deposits in cerebellum and } \\
\text { brainstem. }\end{array}$ \\
\hline PrPSc type 6 & $<1 \%$ & Sporadic CID & $100 \% \mathrm{MM}$ & 3 months & $\begin{array}{l}\text { Spongiform change in cerebral cortex basal ganglia and cerebellum. Synaptic deposits in } \\
\text { cerebellum and brainstem without plaques. }\end{array}$ \\
\hline
\end{tabular}

Table 2: Different molecular variants have their own clinical, pathological and immunohistochemical signatures, adapted from Hill et al. 2003 [10]. MM: methionine homozygote; MV: methionine/valine heterozygote; VV: valine homozygote; vCJD: variant Creutzfeldt-Jakob disease.

In recent decades, efforts have been made to advance in the use of biomarkers to allow an early diagnosis of the different prionopathies. Neurophysiological and neuroimaging biomarkers and different cerebrospinal fluid (CSF) analytes (14-3-3 protein and total tau) have been progressively incorporated into the diagnostic criteria. Special mention should be made of the real-time quaking induced conversion (RT-QuIC) technique for the detection of prion protein in $\mathrm{CSF}$, a technique with the most promising results for the accurate premortem diagnosis of sCJD and other prionopathies, which is already incorporated into the latest diagnostic criteria [3](Table 1). Despite its promising results, the RT-QuIC technique is not universally available; therefore, research into other more accessible biomarkers with potentially high diagnostic performance has continued over the last few years.

This narrative review aims to examine the currently accepted neurophysiological, neuroimaging and cerebrospinal fluid (CSF) biomarkers for diagnosis and investigate alternative CSF and peripheral blood biomarkers that have been recently proposed. We highlight those biomarkers that are more easily accessible, including blood biomarkers, which would truly represent a diagnostic revolution in prionopathies. The existing differences in biomarker performance between different prionopathies will also be emphasized, although it is true that most of the work reviewed has focused on sCJD.

\section{Methodology:}

We performed a literature review using PubMed and Web of Science (WOS), combining the Mesh Terms "Prion Disease" AND “Biomarkers" (Figure 2). We did not apply any time restriction and included original and review articles with data from human subjects (articles reporting only animal data have been excluded) written in English, Spanish or French available on $13^{\text {th }}$ of January 2022. We selected articles with abstracts available in PubMed or WOS. After reading the titles and abstracts, those papers that met eligibility criteria were selected for fulltext revision. Those papers specifically dealing with diagnosis of prion diseases and specifically referring to biomarker utility were included for this review. 


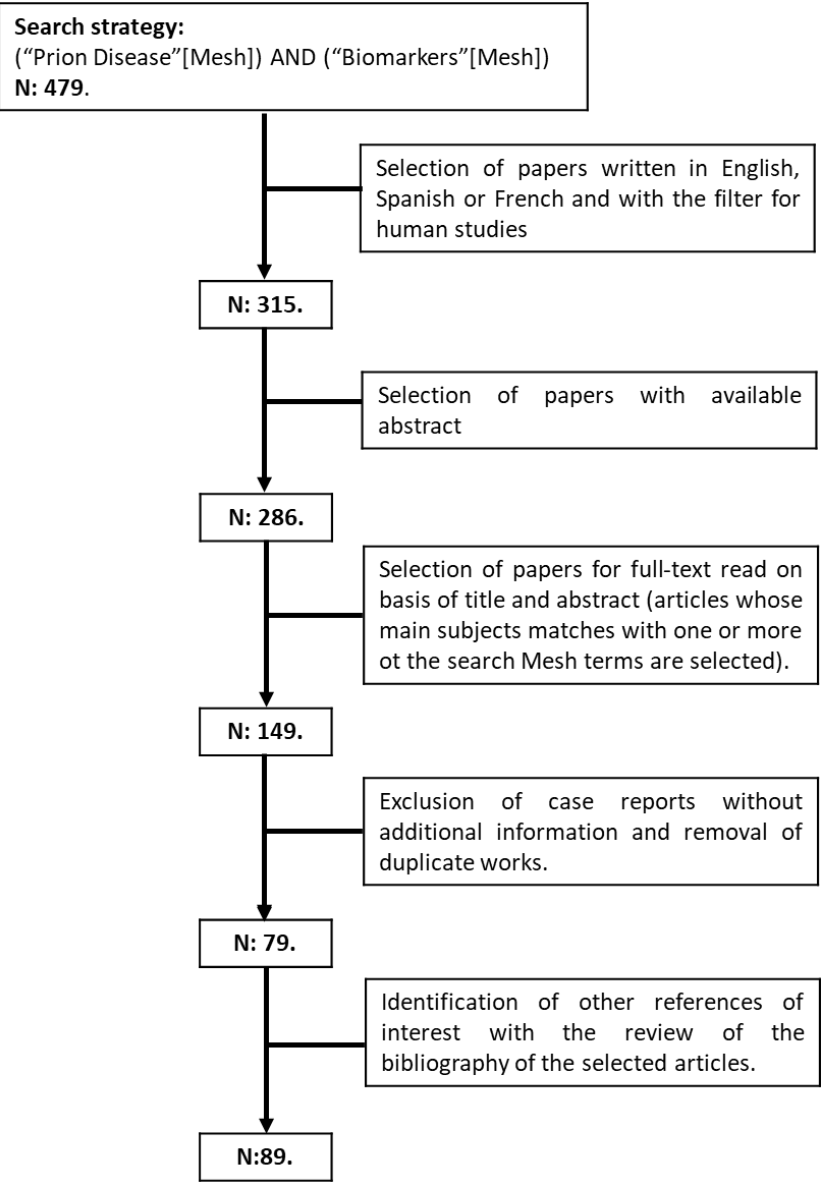

Figure 2: Flowchart of search strategy.

\section{Neurophysiological biomarkers:}

\section{Electroencephalogram (EEG):}

Periodic sharp-wave complexes (PSWCs) characterized by strictly periodic cerebral potentials at a frequency of $1 \mathrm{~Hz}$, generalized and/or lateralized complexes, are the typical EEG finding commonly associated with SCJD. PSWCs tend to disappear during sleep and may be attenuated by some psychotropic drugs [11]. PSWCs are observed in 67-95\% of patients with sCJD, with a sensitivity of $65 \%$ and specificity of $90 \%[12,13]$. In turn, the main background frequency and the $\alpha / \theta$ power ratio in quantitative EEG seems to be related to clinical progression and has been suggested as a useful tool for follow-up monitoring in prion diseases [14]. EEG could be also useful for the detection of non-convulsive status epilepticus, which, although infrequent, has an increased risk in some prionopathies such as SCJD [3].

Advantages: EEG is an economically accessible and safe technique. It is available in most healthcare centers and can be performed repeatedly during clinical follow-up if required.

Limitations: The diagnosis performance of EEG improves with the clinical course of the disease. Therefore, it is a biomarker that is mainly related to the late symptomatic phases of SCJD. In early stages of the disease, unspecific alterations such as diffuse slowing and frontal rhythmic delta activity (FIRDA) are more frequent [11]. Among the other limitations, it should be noted that similar alterations have been described in other neurodegenerative dementias, such as Alzheimer's disease (AD) and Lewy body dementia (LBD), although less frequently. It is also 
noteworthy that the probability of detection of PSWC is much lower in other prionopathies such as FFI or GSS and even in MV2, VV2 and MM2 forms of sCJD [3,13,15].

\section{Polysomnogram (PSG):}

In cases of familiar or sporadic fatal insomnia the demonstration of an early and progressive reduction of total sleep time, the loss of sleep spindles and K-complexes, the disruption of normal sleep structure, sleep fragmentation, and periods of subwakefulness interrupted by brief episodes of REM sleep with or without atonia, often associated with dream enactment behavior, is a diagnostic criterion [16]. In the case of $\mathrm{SCJD}$, sleep anomalies are not recognized as a diagnostic criterion, although it is common to detect loss of normal sleep EEG architecture, sleepdisordered breathing [17] and periodic leg movement disorders in the PSG [18].

Advantages: A non-invasive technique with high diagnostic performance for both sporadic and familiar fatal insomnia.

Limitations: Not universally accessible and not useful for differential diagnosis of the most frequent causes of rapidly progressive neurodegenerative dementias apart from fatal insomnia.

\section{Neuroimaging biomarkers:}

\section{Brain magnetic resonance (MR):}

The presence of hyperintensities in $\mathrm{T} 2$ and fluid attenuated inversion recovery imaging (FLAIR) sequences are frequent in MR of SCJD specially involving basal ganglia [12], as well as the restriction of diffusion (DWI) in at least two cortical regions (ribboning) or/and restricted diffusion predominantly in the caudate nucleus, putamen and/or thalamus $[3,13,19,20]$. However, these typical signs on MR are not pathognomonic of SCJD and could also be induced, even rarely, by toxic metabolic encephalopathies, progressive multifocal dementia, autoimmune encephalitis, CNS lymphoma, vasculitis and infectious etiologies [20].

The MR pattern could also be useful, mainly when combined with PRNP polymorphism, to differentiate sCJD molecular subtype [13]. In the MM1 subtype of SCJD, the caudate nucleus has unilateral or bilateral asymmetrical involvement and the involvement of the thalamus is more frequent in VV2 and MV2 subtypes [21]. The presence of pulvinar sign (high signal on FLAIR and DWI) is highly suggestive of vCJD [3,22]. Moreover, altered diffusion in the striatum, thalamus and frontal and occipital cortices has been reported in GSS [5]. Sensitivity for SCJD diagnosis using MR varies according to different studies between 80 and $92 \%$; the same is true for specificity, with a range between 74 and $98 \% \quad[3,23,24]$. Recently, the use of MR spectroscopy to determine the $\mathrm{N}$-acetylaspartate (NAA)/Creatine $(\mathrm{Cr})$ ratio has been suggested as a useful parameter for predicting clinical course in $\mathrm{SCJD}$, as lower $\mathrm{NAA} / \mathrm{Cr}$ is related to shorter disease duration [25].

Advantages: Structural neuroimaging is a mandatory test for the differential diagnosis of cognitive impairment and, in the cases of rapidly progressive dementias, the MR is crucial. Changes in restriction occur early in the context of sCJD [3,26]. In contrast with EEG, the MR diffusion abnormalities are an early phenomenon, being detectable at least one year before the onset of symptoms in asymptomatic PRNP mutation carriers [27], making it useful for an early diagnosis.

Limitations: At the time of the acquisition of the MR, a clinical suspicion of possible prion disease must be reported because is advisable to perform an MR with a specific protocol including diffusion sequences (DWI/ADC). 


\section{Fluorodesoxyglucose positron emission tomography (PET-FDG):}

Decreased glucose metabolism in the neocortex affecting extensive cortical regions (frontal; parietal and occipital cortices) and basal ganglia has been reported in SCJD but does not seem to be useful for differential diagnosis with other neurodegenerative dementias [28]. However, the hypometabolism of medial temporal area seems to be significantly less frequent compared to other neurodegenerative dementias [28]. Instead, it may be useful for the diagnosis of infrequent forms of sporadic fatal insomnia, where hypometabolism in the thalamic region is early and characteristic $[3,5]$.

Advantages: It could be useful for helping with the diagnosis of sporadic fatal insomnia.

Limitations: It is an expensive test that is not usually performed in cognitive decline screening. There are no specific hypometabolism patterns that could be useful for diagnosing SCJD or performing a differential diagnosis with other prionopathies.

\section{Genetics:}

PRNP gene sequencing is the primary diagnostic technique in genetic prion disease. PRNP mutations account for $10-15 \%$ of all human prion syndromes [3]. The detection of PRNP gene mutations can be performed by sequencing DNA from patient blood specimens or a decedent's unfixed autopsy tissue. All of the genetic forms of prion disease are linked to PRNP mutations and include point mutations, octapeptide repeat insertions and deletions. Many different mutations have been linked to genetic CJD, although the most common worldwide is E200K [2]. The penetrance of PRNP mutations is assumed to be close to $100 \%$ although real-life data are lacking. In the specific case of the E200K mutation, the most widespread, significant variability has been detected with penetrance ranging from 60 to $90 \%$ among different populations [2]. D178N mutation is present in all families with FFI. In individuals of European ancestry, 5 variants account for up to $85 \%$ of the pathogenic PRNP variants (Table 3). Therefore, the first step in genetic analysis is to determine whether these variants exist and, if not, the entire gene should be sequenced [2].

\begin{tabular}{|c|c|c|c|c|c|}
\hline $\begin{array}{c}\text { PRNP } \\
\text { variants }\end{array}$ & $\begin{array}{l}\text { DNA } \\
\text { nucleotide } \\
\text { change }\end{array}$ & $\begin{array}{l}\text { Predicted } \\
\text { Protein } \\
\text { Change }\end{array}$ & Related prionopathy & Phenotype & Expected survival (median) \\
\hline P102L & c. $305 C>T$ & $\begin{array}{l}\text { Proline to leucine } \\
\text { substitution at } \\
\text { codon } 102\end{array}$ & GSS & $\begin{array}{l}\text { Ataxia }(100 \%) \text {, pyramidal }(75 \%) \text {, dementia }(62 \%) \text {, } \\
\text { extrapiramidal }(50 \%) \text {, myoclonus }(25 \%) \text {. } \\
\text { Others: dysarthria, sleep and sensory disturbances. }\end{array}$ & 40 months. \\
\hline D178N & c. $532 \mathrm{G}>\mathrm{A}$ & $\begin{array}{l}\text { aspartic acid to } \\
\text { asparagine } \\
\text { substitution at } \\
\text { codon } 178\end{array}$ & $\begin{array}{l}\text { FFI and genetic CID } \\
\text { (Depends on the allele on } \\
\text { codon 129. M allele: FFI, } \\
\text { and V allele: genetic CJD) }\end{array}$ & $\begin{array}{l}\text { Dementia (96\%), myoclonus (89\%), ataxia }(82 \%) \text {, } \\
\text { extrapyramidal }(82 \%) \text {, pyramidal }(79 \%) \text {, cortical blindness } \\
\text { (79\%). } \\
\text { Others: sleep disturbances, dysarthria, weight loss and } \\
\text { hiperhidrosis. }\end{array}$ & $\begin{array}{l}15 \text { months (earlier onset and } \\
\text { shorter duration of symptomatic } \\
\text { disease in genetic CJD). }\end{array}$ \\
\hline V180I & c. $538 \mathrm{G}>\mathrm{A}$ & $\begin{array}{l}\text { Valine to } \\
\text { isoleucine change } \\
\text { at codon } 180\end{array}$ & Genetic CID & $\begin{array}{l}\text { Dementia (100\%), extrapyramidal (54\%), pyramidal }(46 \%) \text {. } \\
\text { Others: akinetic mutism }(57 \%) \text { and psychiatric }(50 \%) \text {. } \\
\text { Cortical blindness, myolconus and ataxia are more } \\
\text { infrequent. }\end{array}$ & $\begin{array}{l}16,4 \text { months (wide range of } \\
\text { survival). }\end{array}$ \\
\hline E200K & c.598G $>A$ & $\begin{array}{l}\text { Glutamic acid to } \\
\text { lysine substitution } \\
\text { at codon } 200\end{array}$ & Genetic CID & $\begin{array}{l}\text { Ataxia }(100 \%) \text {, dementia }(95 \%) \text {, myoclonus }(85 \%) \text {, } \\
\text { pyramidal }(70 \%) \text {, cortical blindness }(70 \%) \text {, extrapyramidal } \\
(65 \%) \text {. } \\
\text { Ohters: dysarthria, sleep disturbances and weight loss. }\end{array}$ & $\begin{array}{l}5 \text { months (wide range of survival 1- } \\
74 \text { months). }\end{array}$ \\
\hline V210I & c. $628 \mathrm{G}>\mathrm{A}$ & $\begin{array}{l}\text { Valine } \\
\text { isoleucine } \\
\text { substitution } \\
\text { codon } 210\end{array}$ & Genetic CID & $\begin{array}{l}\text { Ataxia }(100 \%) \text {, dementia }(92 \%) \text {, myoclonus }(92 \%) \text {, } \\
\text { extrapyramidal }(92 \%) \text {, cortical blidness }(85 \%) \text {, pyramidal } \\
(72 \%) \text {. } \\
\text { Others: dysarthria and sensory symptoms. }\end{array}$ & 4 months (wide range of survival). \\
\hline
\end{tabular}

Table 3: Summary of the most frequent $P R N P$ variants. Adapted from Ladogana et al. 2018 [2]. 
In addition, the polymorphism of codon 129 of the PRNP gene has potential relevance as it may influence the susceptibility to both variant and sporadic forms of CJD: 85-95\% of sCJD cases are methionine homozygous at codon 129 compared to $49 \%$ in healthy controls [2,13]. However, the codon 129 polymorphism has primarily been investigated in research studies and is not currently used in the diagnostic work-up of prion disease. Interestingly, stratifying patients by codon 129 polymorphism could have a possible role in future clinical trials [13].

\section{Cerebrospinal fluid (CSF) biomarkers:}

\section{Biochemical analysis:}

No differences in the amount of proteins, glucose concentration and total cell number assessed in CSF are detected in prion diseases compared to controls [29].

Advantages: The existence of significant biochemical alterations in CSF may help to check for other etiologies, e.g., inflammatory.

Limitations: Lumbar puncture is considered an invasive test, even if it is currently performed in clinical practice for the early diagnosis of neurodegenerative disorders such as AD.

\section{CSF surrogate biomarkers:}

\subsection{4-3-3 Protein:}

The gamma-isoform of the 14-3-3 protein (14-3-3 gamma) is expressed in neurons, could be a specific marker for neuronal damage and is useful for SCJD diagnosis [30-32]. The pathological mechanisms leading to the accumulation of 14-3-3 protein in CSF are not fully understood; however, neuronal loss followed by cell lysis is assumed to cause the increase in 14-3-3 levels [33]. Currently, the detection of increased 14-3-3 protein in CSF is used as a molecular diagnostic criterion for patients that are clinically compatible with SCJD [33]. The diagnosis performance is lower for genetic forms of prion diseases and also for sporadic fatal insomnia [34,35]. The diagnostic performance of quantitative enzyme-linked immunosorbent (ELISA) assay for 14-3-3 is higher in comparison with western blotting (WB) [30,36]. Combination with other surrogate biomarkers such as the determination of total tau ( $\mathrm{t}$-tau) and the ratio of $\mathrm{t}$ tau/phosphorylated tau (p-tau) significantly increases the specificity [9,32,37-39].

Advantages: It has high sensitivity (86-97\%) for SCJD [40-42] (Figure 3). Combination with t-tau and the ratio of $\mathrm{t}$-tau/p-tau has very good sensitivity and specificity and is more accessible compared to other techniques such as RT-QuIC.

Limitations: Protein 14-3-3 is not as specific as was initially thought [12]; specificity could vary between 75.6 and $91 \%$ for sCJD [38]. Acute neurological conditions such as stroke, status epilepticus or inflammatory encephalopathies can also increase 14-3-3 protein levels [43]. In turn, it shows a low performance for the diagnosis of infrequent prion diseases. 


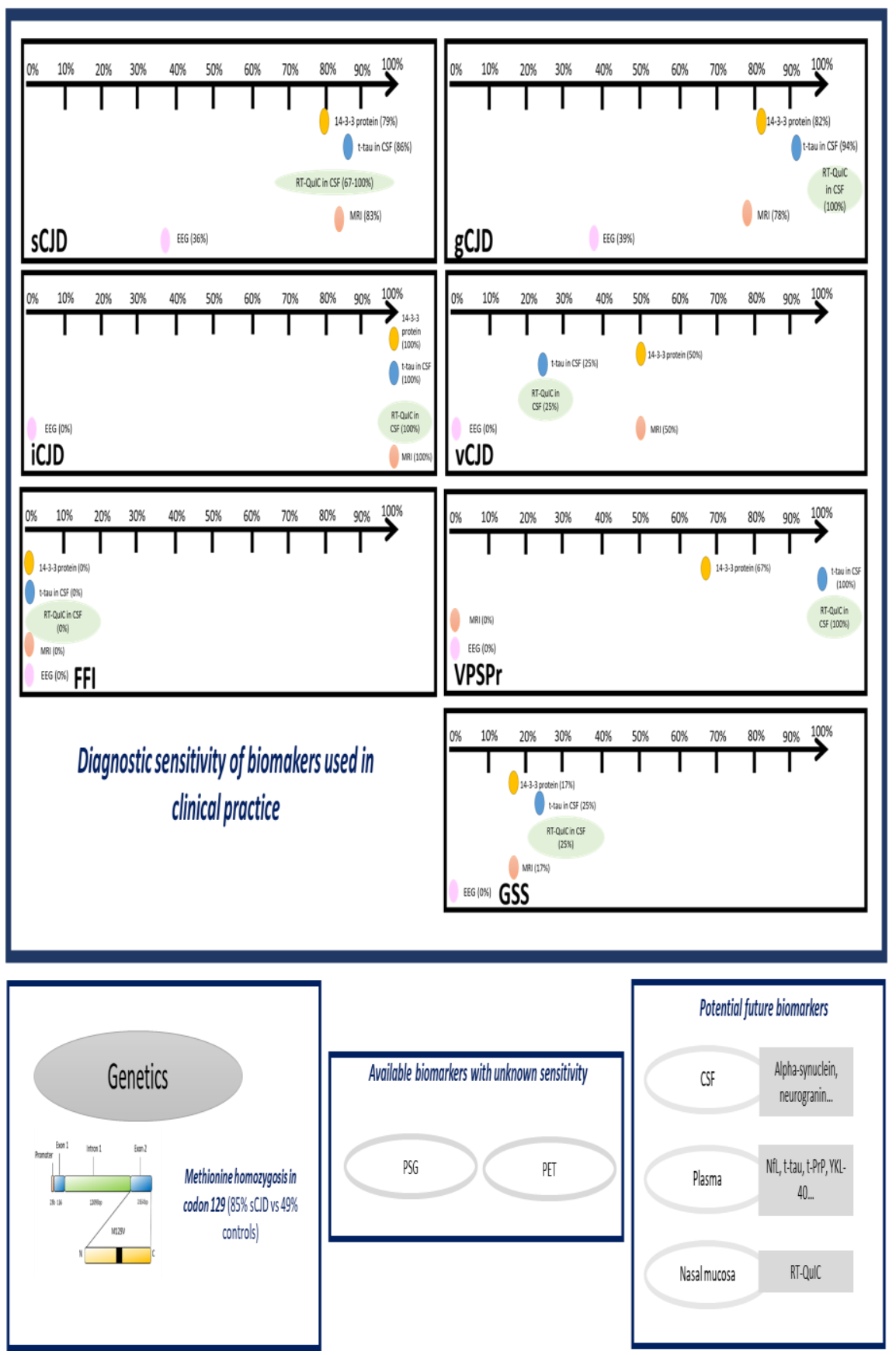

Figure 3: Biomarkers used in clinical practice and their diagnostic sensitivity for prion diseases, and potential future biomarkers. sCJD: sporadic Creutzfeldt-Jakob disease; gCJD: genetic Creutzfeldt-Jakob disease; iCJD: iatrogenic Creutzfeldt-Jakob disease; vCJD: variant CreutzfeldtJakob disease; FFI: fatal familial insomnia; VPSPr: Variably protease-sensitive prionopathy; GSS: Gerstmann-Sträusller-Scheinker; EEG: electroencephalogram; MRI: magnetic resonance imaging; PSG: polysomnogram; PET: positron emission tomography; PET: positron emission tomography.

\subsection{Total tau (t-tau) and total tau/phosphorylated tau (t-tau/p-tau) ratio:}

Elevation of CSF t-tau levels is correlated with axonal neurodegeneration rate in many different neurological conditions, while p-tau is increased in AD but not in other neurodegenerative disorders. The determination of levels of $\mathrm{t}$-tau and ratio of $\mathrm{t}$-tau/p-tau could be useful for the 
diagnosis of CJD, preferably combined with other diagnostic tools [12,44]. Sensitivity and specificity vary depending on the cut-off point established for both $\mathrm{t}$-tau and $\mathrm{t}$-tau/p-tau ratio values but could achieve very high sensitivity $(85 \%)$ and specificity $(98.6 \%)$, both of which are higher compared to the 14-3-3 protein performance [12,45-49]. In turn, the most highly elevated levels of $\mathrm{t}$-tau are observed in the MM1, MV1 and VV2 types with classical symptomatology [50]. Therefore, it has been suggested that $\mathrm{t}$-tau can be used in the diagnostic assessment of prion protein type when the codon 129 genotype is known and could provide valuable information for physicians about the prognosis [51]. The increase in $\mathrm{t}$-tau and $\mathrm{t}$-tau $/ \mathrm{p}$-tau is related to a shortened life expectancy, which could be explained because t-tau reflects neuronal damage $[1,44,50,52]$ and $t$-tau levels continue to increase during the progression of the disease [53]. Indeed $t$-tau levels correlate with the disease burden assessed by cortical involvement evaluated by DWI sequence of MR [54].

Advantages: High specificity for $\mathrm{t}$-tau and $\mathrm{t}$-tau/p-tau ratio for sCJD. Diagnostic performance improves for both genetic and sporadic CJD if combined with 14-3-3 protein [39,55,56].

Limitations: $t$-tau could be increased in other neurodegenerative conditions but not as much as in prionopathies.

\subsection{Neurofilament light chain protein $(\mathrm{NfL})$ :}

$\mathrm{NfL}$ is a neuronal cytoskeleton component and is released when there is neuronal damage in a wide range of conditions, making this a very good biomarker of neurodegeneration [57,58]. NfL is increased in all SCJD subtypes, including those which typically show low values of $\mathrm{t}$-tau and negative protein 14-3-3 (sCJD MV2K, MM2C and gCJD E200K) [4,59]. It has an outstanding sensitivity to detect SCJD, higher than $95 \%$, but a very low specificity of $43.1 \%[9,60]$.

Limitations: Low specificity makes it less useful compared to the determination of $t$-tau or the combination of $\mathrm{t}$-tau or ratio $\mathrm{t}$-tau/p-tau $+14-3-3$ protein in the differential diagnosis of rapidly progressive dementias [9].

Advantages: Due to high sensitivity, this could be useful combined with other surrogate biomarkers for the early diagnosis of prionopathies.

\subsection{Other biomarkers:}

Alpha synuclein, a neuronal protein especially abundant at presynaptic regions, stands out among other promising surrogate biomarkers. Its levels are increased in both genetic and sporadic forms of CJD, with good diagnostic performance (sensitivity $98 \%$ and specificity $97 \%$ ); in addition, there is an inverse correlation between alpha synuclein levels and disease duration in CJD [57,61-63]. In turn, neurogranin, related to synaptic plasticity, has been shown to be increased in SCJD compared to controls and other neurodegenerative dementias with a diagnostic yield similar to 14-3-3 protein from the early stages of the disease, without significant variations with disease progression [4]. It has been speculated that neurogranin levels could be useful to differentiate between different subtypes of CJD (different concentrations having reported according to the clinicopathological subtypes) [4]. Interestingly, it has been reported that ubiquitin, which marks neuritic damage, dysfunctional protostasis and neuroinflammation, has higher concentrations in CJD than in controls and other neurodegenerative dementias, and especially in less frequent forms of sCJD such as $\mathrm{MM}(\mathrm{V}) 1[64,65]$. One study has also shown higher levels of calmodulin, a ubiquitous calcium-binding protein, in SCJD compared to other neurodegenerative dementias particularly in those with higher levels of $\mathrm{t}$-tau [66]. 
Markers related to oxidative stress have also been postulated, as would be the case for mitochondrial malate dehydrogenase 1 (MDH1). The increase in MDH1 would have a sensitivity of $97.5 \%$ and specificity of $95.6 \%$ for the diagnosis of SCJD with positive correlation for t-tau and 14-3-3 protein concentrations according to preliminary data from few studies with small or very heterogeneous samples $[67,68]$, that must be confirmed in future studies previous to its future possible use in clinical practice.

In turn, a single study indicates that glial biomarkers such as YKL-40, CHIT-1 and GFAP are significantly increased in the VV2 form of CJD compared to other neurodegenerative dementias, with a positive correlation with symptomatic progression of the disease [69]. An increase in these biomarkers is even described in presymptomatic cases of GSS [69].

Biomarkers related to iron metabolism, such as transferrin, have also been studied. A single study has postulated that elevated transferrin could be used in combination with $\mathrm{t}$-tau to increase its diagnostic performance [70].

Advantages: The discovery of new biomarkers related to different pathophysiological processes can help us to better understand the disease itself and thus identify possible therapeutic targets. Limitations: At present, none of these biomarkers are approved for use either in isolation or in combination with core biomarkers in neurogenerative diseases. Further studies are needed to support the benefit of the applicability in clinical practice of any of them.

\section{CSF prion proteins:}

\subsection{Total PrP}

Total PrP levels in the CSF of patients with prion disease tend to be reduced compared to controls. It has been speculated that this may result from the sequestration of soluble monomeric protein into aggregates in the brain (analogous to the proposed mechanism for reduction of CSF A $\beta 1-42$ in AD). Specificity for diagnosing prionopathies of reduced total PrP in CSF seems to be moderate and unlikely to be used for differential diagnosis with other causes of rapidly progressive dementia at least if not combined with surrogate CSF biomarkers such 14-3-3 protein and t-tau or ratio t-tau/p-tau $[33,57,71]$. On the other hand, it has been suggested that it could have potential applicability for monitoring response to future disease-modifying treatments because there are significant differences in genetic forms of CJD between PRNP mutations carriers and non-carriers years before of the symptom onset and levels of test-retest of total PrP are stable during the follow-up [72].

Advantages: This biomarker directly reflects the pathophysiology of prion diseases and therefore has a potential role in the follow-up of possible future treatments.

Limitations: It has suboptimal performance, not superior to that described for surrogate biomarkers with applications in clinical practice. Therefore, it is unlikely to be indicated as a diagnostic biomarker in the future.

\subsection{Prion Real-Time Quaking-Induced Conversion (RT-QuIC)}

Aside from brain biopsy, RT-QuIC, an ultrasensitive in vitro PrPSc amplification assay (Figure 4), is the only disease-specific antemortem diagnostic biomarker that directly detects the pathological prion protein (PrPSc) and has also been incorporated since 2018 in the current diagnostic criteria [13,37,38,58,73-75]. A very high sensitivity (80-96\%) and virtually full specificity (99-100\%) has been reported for RT-QuIC for sCJD (Figure 3). However, the sensitivity is lower in MM1, the most frequent subtype of sCJD [37], and is even lower in genetic forms of CJD, GSS and FFI as well as in sporadic fatal insomnia. The most plausible explanation 
for this finding is strain variability [73,76]. Nevertheless, the RT-QuIC performance continues to be higher compared to 14-3-3 and also to the combination of 14-3-3 ant t-tau or $\mathrm{t}$-tau/p-tau ratio for genetic forms of CJD, GSS and FFI [77]. In contrast, it has not demonstrated an ability to differentiate between different subtypes of sCJD [78]. In turn, RT-QuIC presents increased costs and less inter-laboratory standardization data is available compared to the use of approved surrogate biomarkers (14-3-3 protein and t-tau) [79].

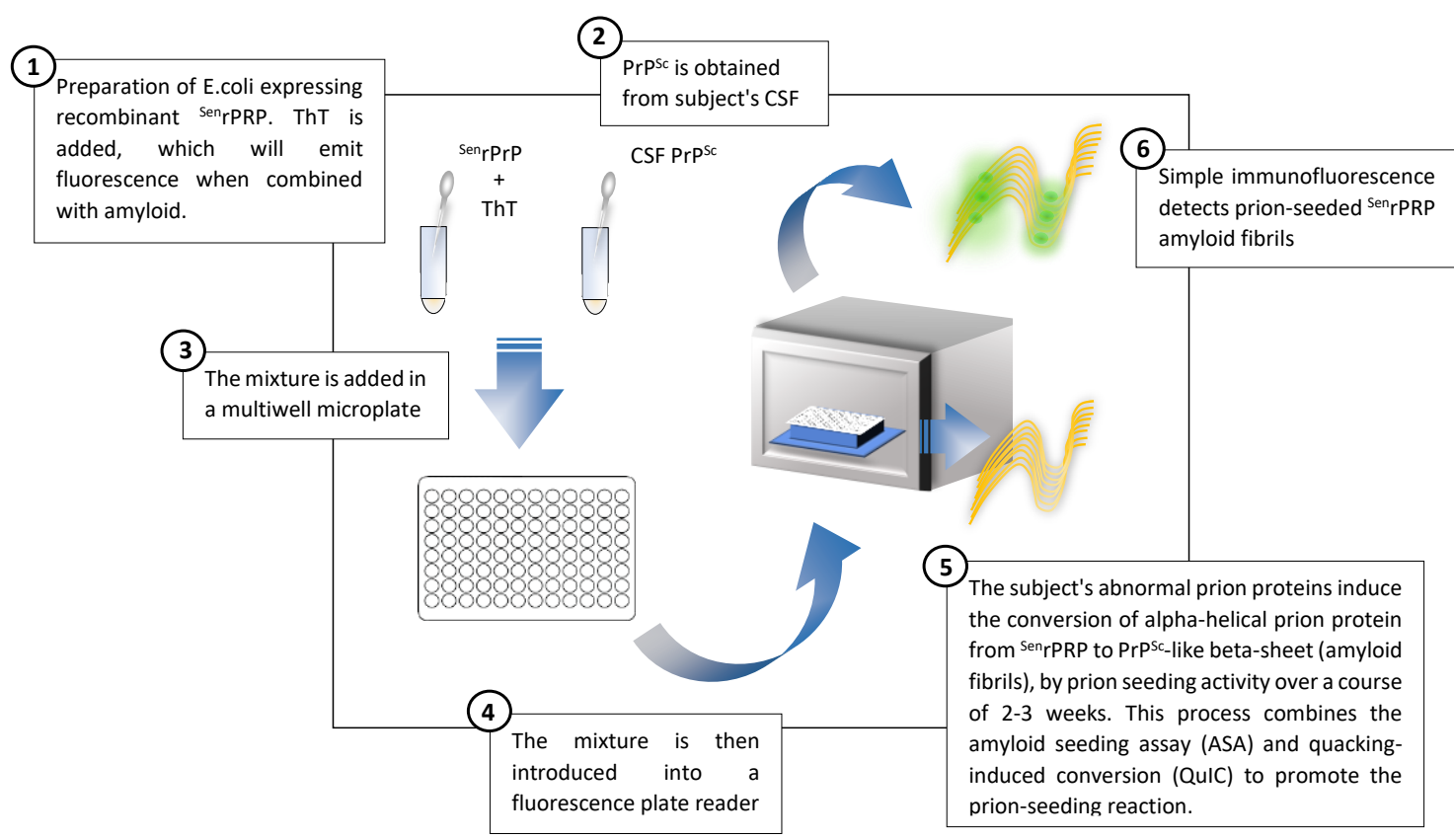

Figure 4: Description of the Prion Real-Time Quaking-Induced Conversion technique applied to the diagnosis of prion diseases, adapted from Orrù et al. 2017 [80].

Advantages: The ability to detect prion protein with high sensitivity and specificity of almost $100 \%$. Included as a diagnostic criterion.

Limitations: Technically more complex than the determination of other surrogate biomarkers that are measurable in CSF (14-3-3 protein and total tau), accessible in fewer hospitals. Poorer performance for atypical variants of SCJD and genetic forms of CJD, GSS and familial and/or sporadic fatal insomnia.

\section{Plasma biomarkers}

1. NfL:

Increased levels of plasma NfL have been reported in CJD, significantly higher than in other neurodegenerative dementias (AD, LBD and frontotemporal dementia -FTD-) and obviously compared to controls. One study has shown an AUC of 0.93 to discriminate CJD from non-CJD dementias [81] and another has reported a sensitivity of $100 \%$ and specificity of $85.5 \%$ for the diagnosis of different prionopathies (sporadic, genetic and iatrogenic CJD and GSS) [57,82]. However, it has been suggested that performance of NfL is better in CSF compared to plasma [83]. The increase in plasma NfL occurs in the early stages of the disease, before symptoms onset, and it seems to be always altered if the prion conversion assay is positive in CSF. The levels of NfL continue to increase with the symptomatic progression of the disease [82]. 
Advantages: An accessible biomarker with a huge number of studies suggesting its utility for discriminating neurodegenerative vs non-neurodegenerative dementias. Altered from the early stages of disease, so therefore useful for early diagnosis.

Limitations: Not a specific biomarker of prion diseases; also increased in other neurodegenerative dementias, although not to the same extent.

\section{2. t-tau:}

Plasma t-tau levels are higher in CJD, described in sporadic, iatrogenic and genetic forms, compared not only to controls, but also significantly when compared to other neurodegenerative dementias [57,84]. t-tau is particularly increased in SCJD patients who are homozygous for methionine at codon 129 of PRNP gene [84]. Plasma t-tau seems to have a moderate association with disease duration, offering a moderate survival prediction capacity [85]. One study has reported a sensitivity of $84.6 \%$ and specificity of $96.2 \%$ [82], but it seems that both sensitivity and specificity are lower in general for plasma t-tau compared to CSF t-tau [83].

Advantages: This could be useful to discriminate from non-neurodegenerative causes of cognitive decline.

Limitations: It is an unspecific biomarker of neurodegeneration that does not clearly improve the performance of plasma NfL.

\section{YKL-40:}

Increased levels of plasma YKL-40 have been detected in different sporadic and genetic forms of prionopathies compared to controls. Higher levels are detected in later stages of the disease [86]. Due to the low capacity to discriminate from other neurodegenerative dementias and moderate ability to distinguish from healthy controls, YKL-40 does not seem to be a good diagnostic biomarker but can have a role in disease monitoring [86].

Advantages: Could be a potential plasma biomarker related with progression of the disease.

Limitations: Very discrete capacity to discriminate prion diseases from other neurodegenerative diseases; doubtful utility as an add biomarker for diagnosis.

\section{MicroRNA:}

The blood microRNA profile has been suggested as a complementary test to use together with plasma neurodegeneration biomarkers. One study with a small sample size has shown different microRNA expression in sCJD compared not only to controls but also to AD [87].

Advantages: Could be another non-invasive biomarker of SCJD.

Limitations: Very limited data; does not seem to be applicable in clinical practice, at least in a short term.

\section{Total Prion Protein (t-PrP):}

The existence of vascular pathology with a loss of integrity of the blood brain barrier (BBB) has been described in more than $40 \%$ of brains with prion disease. With the loss of BBB integrity, it is expected that dying endothelial cells in the intracranial capillary vascular system and specially dying neurons can release PrP to the blood circulation system. Indeed, increased levels of plasma $\mathrm{t}-\mathrm{PrP}$ have been reported in sporadic, genetic and variant CJD. However, the increase in plasma $\mathrm{t}-\mathrm{PrP}$ is not specific to prion diseases because it has also been reported in other conditions such as AD, FTD, or LBD [88]. Therefore, it seems to be useful to discriminate between neurodegenerative and non-neurodegenerative dementias, but not at least clearly between prion diseases and other neurodegenerative disorders, even though higher levels have been reported in classical sCJD compared to other neurodegenerative dementias [88]. Interestingly, there is a 
dissociation between t-PrP CSF and plasma levels in SCJD, which are increased in plasma but decreased in CSF $[57,88]$. The presence of higher t-PrP levels in SCJD cases harboring MM and VV at PRNP codon 129 compared to MV carriers has also been reported, suggesting a better performance for homozygous carriers [88]. A mild association is reported between CSF markers of neuronal injury (14-3-3 protein and $\mathrm{NfL}$ ) and plasmatic t-PrP, suggesting that plasma t-PrP might be regarded as a biomarker of neurodegeneration, in contrast to CSF t-PrP, which probably reflects pathogenic $\operatorname{PrP}$ aggregation occurring in prion disease patients. Nonassociation has been reported between plasma t-PrP and the stage or disease duration, which argues against a potential use of this marker for prognostic purposes [88].

Advantages: It is possible to assess this biomarker in an accessible fluid, so invasive techniques are not required. The increase of $\mathrm{t}-\mathrm{PrP}$ in the plasma of $\mathrm{CJD}$ (sporadic, acquired and genetic) can be detected from the early stages and does not vary between different stages of the disease, making it potentially useful as an early diagnosis biomarker.

Limitations: It is not specific for CJD diagnosis and we do not have information about less prevalent prionopathies. This biomarker seems to be more related with neurodegeneration.

\section{Nasal mucosa:}

RT-QuIC performed in the samples obtained by nasal brushing, a less invasive technique compared to lumbar puncture, has shown a very high diagnosis accuracy according to preliminary data, with a sensitivity of $97 \%$ and specificity of $100 \%$; this is a better performance compared to RT-QuIC in CSF [89]. It has been suggested that the combination of CSF RT-QuIC and RT-QuIC from a sample of nasal mucosa could increase the sensitivity from the early diagnosis of CJD to almost $100 \%$ [38].

Advantages: Obtaining a nasal mucosal sample would be safer and better tolerated by patients than lumbar puncture. If the preliminary data are confirmed, it could potentially replace CSF as a sample for RT-QuIC or at least, and this ultimately more likely, allow to increase diagnostic confidence in those subjects with high suspicion of prion disease with negative RT-QuIC in CSF, being able to detect some false negatives in this.

Limitations: Only preliminary data are still available that do not allow its practical clinical applicability. On the other hand, in many subjects lumbar puncture will continue to be performed for screening of other neurodegenerative dementias. Therefore, it seems complicated that the nasal mucosa sample can universally replace lumbar puncture for RT-QuIC study, at least not until other biomarkers with good diagnosis performance for other neurodegenerative dementias are developed for use in nasal mucosa.

\section{Conclusions}

An early and accurate diagnosis of prion diseases, with a clinically progressive course and without modifying treatment, is essential. Therefore, the availability of biomarkers that provide near-total diagnostic certainty proves crucial. The fact that some of these biomarkers show a high yield from an early stage (even in asymptomatic carriers in the genetic forms) can help us to better identify subjects that could be candidates for future therapeutic strategies.

Among the biomarkers available in clinical practice, RT-QuIC in cerebrospinal fluid, is the diagnostic biomarker with the best performance for early diagnosis; preliminary results of the same technique in other tissues such as nasal mucosa are also very promising. Even so, along 
with the determination of RT-QuIC, it is advisable to also request the determination of 14-3-3 protein, $\mathrm{t}$-tau and $\mathrm{p}$-tau, since diagnostic sensitivity will be further increased without any decrease in specificity.

In recent years, there have been fewer advances in neuroimaging and neurophysiology biomarkers but they are no less relevant. Structural neuroimaging (MR has to be obtained preferably) within the etiological study of any neurodegenerative dementia is mandatory and will therefore continue to have a relevant role. Neurophysiological tests will continue to play an essential role in the diagnosis of sporadic or fatal familial insomnia and the electroencephalogram, non-invasive and inexpensive, can remain as an additional diagnostic tool in centers with fewer resources.

For the time being, it does not seem that plasma biomarkers will be applied for the diagnosis of prion diseases due to the inferior performance of all biomarkers studied in the blood with respect to cerebrospinal fluid to discriminate prion diseases from other neurodegenerative dementias. However, they could be useful for monitoring the response to a possible disease-modifying treatment, since assay protocols based on peripheral blood biomarkers as a target response will always be easier to perform than those based on CSF biomarkers.

Author Contributions: Conceptualization, M.A.; methodology, M.A. and I.R.; investigation, M.A. and I.R.; resources, M.A.; data curation, M.A. and I.R.; writingoriginal draft preparation, M.A. and I.R.; writing - review and editing, M.A., MV.Z. and M.M.; visualization, M.A., MV.Z. and M.M.; supervision, M.A., MV.Z. and M.M.; project administration, M.A.; funding acquisition, M.A. All authors have read and agreed to the published version of the manuscript.

Funding: MA acknowledges support from a Río Hortega Fellowship (CM19/00066) by the Carlos III Health Institute.

Institutional Review Board Statement: Not applicable.

Informed Consent Statement: Not applicable.

Data Availability Statement: Not applicable.

Conflicts of Interest: The authors declare no conflicts of interest.

\section{References}

1. Llorens F, Rübsamen N, Hermann P, Schmitz M, Villar-Piqué A, Goebel S, et al. A prognostic model for overall survival in sporadic Creutzfeldt-Jakob disease. Alzheimers Dement. 2020 Oct;16(10):1438-47.

2. Ladogana A, Kovacs GG. Genetic Creutzfeldt-Jakob disease. Handb Clin Neurol. 2018;153:219-42.

3. Hermann P, Appleby B, Brandel J-P, Caughey B, Collins S, Geschwind MD, et al. Biomarkers and diagnostic guidelines for sporadic Creutzfeldt-Jakob disease. Lancet Neurol. 2021 Mar;20(3):235-46. 
4. Blennow K, Diaz-Lucena D, Zetterberg H, Villar-Pique A, Karch A, Vidal E, et al. CSF neurogranin as a neuronal damage marker in CJD: a comparative study with AD. J Neurol Neurosurg Psychiatry. 2019 Aug;90(8):846-53.

5. Marino S, Morabito R, De Salvo S, Bonanno L, Bramanti A, Pollicino P, et al. Quantitative, functional MRI and neurophysiological markers in a case of Gerstmann-Sträussler-Scheinker syndrome. Funct Neurol. 2017;32(3):153-8.

6. Moore RC, Xiang F, Monaghan J, Han D, Zhang Z, Edström L, et al. Huntington Disease Phenocopy Is a Familial Prion Disease. Am J Hum Genet [Internet]. 2001 Dec 1;69(6):1385-8. Available from: https://doi.org/10.1086/324414

7. Brandel J-P, Knight R. Variant Creutzfeldt-Jakob disease. Handb Clin Neurol. 2018;153:191-205.

8. Spencer MD, Knight RSG, Will RG. First hundred cases of variant Creutzfeldt-Jakob disease: retrospective case note review of early psychiatric and neurological features. BMJ. 2002 Jun;324(7352):1479-82.

9. Abu-Rumeileh S, Baiardi S, Polischi B, Mammana A, Franceschini A, Green A, et al. Diagnostic value of surrogate CSF biomarkers for Creutzfeldt-Jakob disease in the era of RT-QuIC. J Neurol. 2019 Dec;266(12):3136-43.

10. Hill AF, Joiner S, Wadsworth JDF, Sidle KCL, Bell JE, Budka H, et al. Molecular classification of sporadic Creutzfeldt-Jakob disease. Brain [Internet]. 2003 Jun 1;126(6):1333-46. Available from: https://doi.org/10.1093/brain/awg125

11. Wieser HG, Schindler K, Zumsteg D. EEG in Creutzfeldt-Jakob disease. Clin Neurophysiol Off J Int Fed Clin Neurophysiol. 2006 May;117(5):935-51.

12. Skillbäck T, Rosén C, Asztely F, Mattsson N, Blennow K, Zetterberg H. Diagnostic performance of cerebrospinal fluid total tau and phosphorylated tau in Creutzfeldt-Jakob disease: results from the Swedish Mortality Registry. JAMA Neurol. 2014 Apr;71(4):476-83.

13. Figgie MPJ, Appleby BS. Clinical Use of Improved Diagnostic Testing for Detection of Prion Disease. Viruses. 2021 Apr;13(5).

14. Franko E, Wehner T, Joly O, Lowe J, Porter M-C, Kenny J, et al. Quantitative EEG parameters correlate with the progression of human prion diseases. J Neurol Neurosurg Psychiatry. 2016 Oct;87(10):1061-7.

15. Matsubayashi T, Akaza M, Hayashi Y, Hamaguchi T, Yamada M, Shimohata T, et al. Focal sharp waves are a specific early-stage marker of the MM2-cortical form of sporadic Creutzfeldt-Jakob disease. Prion. 2020 Dec;14(1):207-13.

16. Wu L-Y, Zhan S-Q, Huang Z-Y, Zhang B, Wang T, Liu C-F, et al. Expert Consensus on Clinical Diagnostic Criteria 
for Fatal Familial Insomnia. Chin Med J (Engl). 2018 Jul;131(13):1613-7.

17. Kang P, de Bruin GS, Wang LH, Ward BA, Ances BM, Lim MM, et al. Sleep Pathology in Creutzfeldt-Jakob Disease. J Clin sleep Med JCSM Ｏff Publ Am ～Acad Sleep Med. 2016 Jul;12(7):1033-9.

18. Dai Y, Shao J, Lang Y, Lv Y, Cui L. Clinical manifestations and polysomnography-based analysis in nine cases of probable sporadic Creutzfeldt-Jakob disease. Neurol Sci Off J Ital Neurol Soc Ital Soc Clin Neurophysiol. 2021 Oct;42(10):4209-19.

19. Macfarlane RG, Wroe SJ, Collinge J, Yousry TA, Jäger HR. Neuroimaging findings in human prion disease. J Neurol Neurosurg Psychiatry. 2007 Jul;78(7):664-70.

20. Sacco S, Paoletti M, Staffaroni AM, Kang H, Rojas J, Marx G, et al. Multimodal MRI staging for tracking progression and clinical-imaging correlation in sporadic Creutzfeldt-Jakob disease. NeuroImage Clin. $2021 ; 30: 102523$.

21. Baiardi S, Magherini A, Capellari S, Redaelli V, Ladogana A, Rossi M, et al. Towards an early clinical diagnosis of sporadic CJD VV2 (ataxic type). J Neurol Neurosurg Psychiatry. 2017 Sep;88(9):764-72.

22. Ioannides P, Karacostas D. Neuroimaging in human prion disease: Searching in the mist. World J Radiol. 2009 Dec;1(1):45-9.

23. Divya KP, Menon RN, Thomas B, Nair M. A hospital-based registry of Creutzfeldt-Jakob disease: Can neuroimaging serve as a surrogate biomarker? Neurol India. 2016;64(3):411-8.

24. Rudge P, Hyare H, Green A, Collinge J, Mead S. Imaging and CSF analyses effectively distinguish CJD from its mimics. J Neurol Neurosurg Psychiatry. 2018 May;89(5):461-6.

25. Kim JH, Choi BS, Jung C, Chang Y, Kim S. Diffusion-weighted imaging and magnetic resonance spectroscopy of sporadic Creutzfeldt-Jakob disease: correlation with clinical course. Neuroradiology. 2011 Dec;53(12):93945.

26. Shiga Y, Miyazawa K, Sato S, Fukushima R, Shibuya S, Sato Y, et al. Diffusion-weighted MRI abnormalities as an early diagnostic marker for Creutzfeldt-Jakob disease. Neurology. 2004 Aug;63(3):443-9.

27. Lee H, Rosenmann H, Chapman J, Kingsley PB, Hoffmann C, Cohen OS, et al. Thalamo-striatal diffusion reductions precede disease onset in prion mutation carriers. Brain. 2009 Oct;132(Pt 10):2680-7.

28. Kim E-J, Cho S-S, Jeong B-H, Kim Y-S, Seo SW, Na DL, et al. Glucose metabolism in sporadic Creutzfeldt-Jakob disease: a statistical parametric mapping analysis of (18) F-FDG PET. Eur J Neurol. 2012 Mar;19(3):488-93.

29. Green AJE, Ramljak S, Müller WEG, Knight RSG, Schröder HC. 14-3-3 in the cerebrospinal fluid of patients with 
variant and sporadic Creutzfeldt-Jakob disease measured using capture assay able to detect low levels of 143-3 protein. Neurosci Lett. 2002 May;324(1):57-60.

30. Matsui Y, Satoh K, Miyazaki T, Shirabe S, Atarashi R, Mutsukura K, et al. High sensitivity of an ELISA kit for detection of the gamma-isoform of 14-3-3 proteins: usefulness in laboratory diagnosis of human prion disease. BMC Neurol. 2011 Oct;11:120.

31. Castellani RJ, Colucci M, Xie Z, Zou W, Li C, Parchi P, et al. Sensitivity of 14-3-3 protein test varies in subtypes of sporadic Creutzfeldt-Jakob disease. Neurology. 2004 Aug;63(3):436-42.

32. Leitão MJ, Baldeiras I, Almeida MR, Ribeiro MH, Santos AC, Ribeiro M, et al. CSF Tau proteins reduce misdiagnosis of sporadic Creutzfeldt-Jakob disease suspected cases with inconclusive 14-3-3 result. J Neurol. 2016 Sep;263(9):1847-61.

33. Torres M, Cartier L, Matamala JM, Hernández N, Woehlbier U, Hetz C. Altered Prion protein expression pattern in CSF as a biomarker for Creutzfeldt-Jakob disease. PLoS One. 2012;7(4):e36159.

34. Ladogana A, Sanchez-Juan P, Mitrová E, Green A, Cuadrado-Corrales N, Sánchez-Valle R, et al. Cerebrospinal fluid biomarkers in human genetic transmissible spongiform encephalopathies. J Neurol. 2009 Oct;256(10):1620-8.

35. Higuma M, Sanjo N, Satoh K, Shiga Y, Sakai K, Nozaki I, et al. Relationships between clinicopathological features and cerebrospinal fluid biomarkers in Japanese patients with genetic prion diseases. PLoS One. 2013;8(3):e60003.

36. Leitão MJ, Baldeiras I, Almeida MR, Ribeiro MH, Santos AC, Ribeiro M, et al. Sporadic Creutzfeldt-Jakob disease diagnostic accuracy is improved by a new CSF ELISA 14-3-3 $\gamma$ assay. Neuroscience. 2016 May;322:398-407.

37. Lattanzio F, Abu-Rumeileh S, Franceschini A, Kai H, Amore G, Poggiolini I, et al. Prion-specific and surrogate CSF biomarkers in Creutzfeldt-Jakob disease: diagnostic accuracy in relation to molecular subtypes and analysis of neuropathological correlates of p-tau and A $\beta 42$ levels. Acta Neuropathol. 2017 Apr;133(4):559-78.

38. Zanusso G, Fiorini M, Ferrari S, Gajofatto A, Cagnin A, Galassi A, et al. Cerebrospinal fluid markers in sporadic Creutzfeldt-Jakob disease. Int J Mol Sci. 2011;12(9):6281-92.

39. Hyeon JW, Kim SY, Lee J, Park JS, Hwang KJ, Lee SM, et al. Alternative application of Tau protein in CreutzfeldtJakob disease diagnosis: Improvement for weakly positive 14-3-3 protein in the laboratory. Sci Rep. 2015 Oct; $5: 15283$.

40. Chohan G, Pennington C, Mackenzie JM, Andrews M, Everington D, Will RG, et al. The role of cerebrospinal 
fluid 14-3-3 and other proteins in the diagnosis of sporadic Creutzfeldt-Jakob disease in the UK: a 10-year review. J Neurol Neurosurg Psychiatry. 2010 Nov;81(11):1243-8.

41. Lemstra AW, van Meegen MT, Vreyling JP, Meijerink PH, Jansen GH, Bulk S, et al. 14-3-3 testing in diagnosing Creutzfeldt-Jakob disease: a prospective study in 112 patients. Neurology. 2000 Aug;55(4):514-6.

42. Schmitz M, Ebert E, Stoeck K, Karch A, Collins S, Calero M, et al. Validation of 14-3-3 Protein as a Marker in Sporadic Creutzfeldt-Jakob Disease ～Diagnostic. Mol Neurobiol. 2016 May;53(4):2189-99.

43. Stoeck K, Sanchez-Juan P, Gawinecka J, Green A, Ladogana A, Pocchiari M, et al. Cerebrospinal fluid biomarker supported diagnosis of Creutzfeldt-Jakob disease and rapid dementias: a longitudinal multicentre study over 10 years. Brain. 2012 Oct;135(Pt 10):3051-61.

44. Llorens F, Karch A, Golanska E, Schmitz M, Lange P, Sikorska B, et al. Cerebrospinal Fluid Biomarker-Based Diagnosis of Sporadic Creutzfeldt-Jakob Disease: A Validation Study for Previously Established Cutoffs. Dement Geriatr Cogn Disord. 2017;43(1-2):71-80.

45. Hamlin C, Puoti G, Berri S, Sting E, Harris C, Cohen M, et al. A comparison of tau and 14-3-3 protein in the diagnosis of Creutzfeldt-Jakob disease. Neurology. 2012 Aug;79(6):547-52.

46. Coulthart MB, Jansen GH, Olsen E, Godal DL, Connolly T, Choi BCK, et al. Diagnostic accuracy of cerebrospinal fluid protein markers for sporadic Creutzfeldt-Jakob disease in Canada: a 6-year prospective study. BMC Neurol. 2011 Oct;11:133.

47. Foucault-Fruchard L, Delaye JB, Morange V, Beaufils E, Duwicquet C, Quadrio I, et al. An automated alert system based on the p-Tau/Tau ratio to quickly inform health professionals upon a suspected case of sporadic Creutzfeldt-Jakob disease. J Neurol Sci. 2020 Aug;415:116971.

48. Llorens F, Villar-Piqué A, Hermann P, Schmitz M, Goebel S, Waniek K, et al. Cerebrospinal fluid nonphosphorylated tau in the differential diagnosis of Creutzfeldt-Jakob disease: a comparative prospective study with 14-3-3. J Neurol. 2020 Feb;267(2):543-50.

49. Meiner Z, Kahana E, Baitcher F, Korczyn AD, Chapman J, Cohen OS, et al. Tau and 14-3-3 of genetic and sporadic Creutzfeldt-Jakob disease patients in Israel. J Neurol. 2011 Feb;258(2):255-62.

50. Gmitterová K, Heinemann U, Krasnianski A, Gawinecka J, Zerr I. Cerebrospinal fluid markers in the differentiation of molecular subtypes of sporadic C Creutzfeldt-Jakob disease. Eur J Neurol. 2016 Jun;23(6):112633.

51. Karch A, Hermann P, Ponto C, Schmitz M, Arora A, Zafar S, et al. Cerebrospinal fluid tau levels are a marker 
for molecular subtype in sporadic Creutzfeldt-Jakob disease. Neurobiol Aging. 2015 May;36(5):1964-8.

52. Karch A, Llorens F, Schmitz M, Arora AS, Zafar S, Lange P, et al. Stratification by Genetic and Demographic Characteristics Improves Diagnostic Accuracy of Cerebrospinal Fluid Biomarkers in Rapidly Progressive Dementia. J Alzheimers Dis. 2016 Oct;54(4):1385-93.

53. Satoh K, Shirabe S, Eguchi H, Tsujino A, Motomura M, Satoh A, et al. Chronological changes in MRI and CSF biochemical markers in Creutzfeldt-Jakob disease patients. Dement Geriatr Cogn Disord. 2007;23(6):372-81.

54. Cohen OS, Chapman J, Korczyn AD, Siaw OL, Warman-Alaluf N, Nitsan Z, et al. CSF tau correlates with the degree of cortical involvement in E200K familial Creutzfeldt-Jakob disease. Neurosci Lett. 2016 Nov;634:76-8.

55. Van Everbroeck B, Quoilin S, Boons J, Martin JJ, Cras P. A prospective study of CSF markers in 250 patients with possible Creutzfeldt-Jakob disease. J Neurol Neurosurg Psychiatry. 2003 Sep;74(9):1210-4.

56. Wang G-R, Gao C, Shi Q, Zhou W, Chen J-M, Dong C-F, et al. Elevated levels of tau protein in cerebrospinal fluid of patients with probable Creutzfeldt-Jakob disease. Am J Med Sci. 2010 Oct;340(4):291-5.

57. Thompson AGB, Mead SH. Review: Fluid biomarkers in the human prion diseases. Mol Cell Neurosci. 2019 Jun;97:81-92.

58. Zerr I, Schmitz M, Karch A, Villar-Piqué A, Kanata E, Golanska E, et al. Cerebrospinal fluid neurofilament light levels in neurodegenerative dementia: Evaluation of diagnostic accuracy in the differential diagnosis of prion diseases. Alzheimers Dement. 2018 Jun;14(6):751-63.

59. Kanata E, Golanska E, Villar-Piqué A, Karsanidou A, Dafou D, Xanthopoulos K, et al. Cerebrospinal fluid neurofilament light in suspected sporadic Creutzfeldt-Jakob disease. J Clin Neurosci Off J Neurosurg Soc Australas. 2019 Feb;60:124-7.

60. Abu-Rumeileh S, Capellari S, Stanzani-Maserati M, Polischi B, Martinelli P, Caroppo P, et al. The CSF neurofilament light signature in rapidly progressive neurodegenerative dementias. Alzheimers Res Ther. 2018 Jan;10(1):3.

61. Llorens F, Kruse N, Schmitz M, Shafiq M, da Cunha JEG, Gotzman N, et al. Quantification of CSF biomarkers using an electrochemiluminescence-based detection system in the differential diagnosis of AD and sCJD. J Neurol. 2015 Oct;262(10):2305-11.

62. Llorens F, Kruse N, Schmitz M, Gotzmann N, Golanska E, Thüne K, et al. Evaluation of $\alpha$-synuclein as a novel cerebrospinal fluid biomarker in different forms of prion diseases. Alzheimers Dement. 2017 Jun;13(6):710-9.

63. Oeckl P, Metzger F, Nagl M, von Arnim CAF, Halbgebauer S, Steinacker P, et al. Alpha-, Beta-, and Gamma- 
synuclein Quantification in Cerebrospinal Fluid by Multiple Reaction Monitoring Reveals Increased Concentrations in Alzheimer's and Creutzfeldt-Jakob Disease but No Alteration in Synucleinopathies. Mol Cell Proteomics. 2016 Oct;15(10):3126-38.

64. Abu-Rumeileh S, Oeckl P, Baiardi S, Halbgebauer S, Steinacker P, Capellari S, et al. CSF Ubiquitin Levels Are Higher in Alzheimer's Disease than in Frontotemporal Dementia and Reflect the Molecular Subtype in Prion Disease. Biomolecules. 2020 Mar;10(4).

65. Steinacker P, Rist W, Swiatek-de-Lange M, Lehnert S, Jesse S, Pabst A, et al. Ubiquitin as potential cerebrospinal fluid marker of Creutzfeldt-Jakob disease. Proteomics. 2010 Jan;10(1):81-9.

66. Chen $\mathrm{C}, \mathrm{Hu} \mathrm{C}$, Zhou W, Chen J, Shi Q, Xiao K, et al. Calmodulin level is significantly increased in the cerebrospinal fluid of patients $\quad$ with sporadic Creutzfeldt-Jakob disease. Eur J Neurol. 2021 Apr;28(4):1134-41.

67. Schmitz M, Llorens F, Pracht A, Thom T, Correia Â, Zafar S, et al. Regulation of human cerebrospinal fluid malate dehydrogenase 1 in sporadic Creutzfeldt-Jakob disease patients. Aging (Albany NY). 2016 Nov;8(11):2927-35.

68. Zerr I, Villar-Piqué A, Schmitz VE, Poleggi A, Pocchiari M, Sánchez-Valle R, et al. Evaluation of Human Cerebrospinal Fluid Malate Dehydrogenase 1 as a Marker in Genetic Prion Disease Patients. Biomolecules. 2019 Nov;9(12).

69. Abu-Rumeileh S, Steinacker P, Polischi B, Mammana A, Bartoletti-Stella A, Oeckl P, et al. CSF biomarkers of neuroinflammation in distinct forms and subtypes of neurodegenerative dementia. Alzheimers Res Ther. 2019 Dec;12(1):2.

70. Herbst A, McIlwain S, Schmidt JJ, Aiken JM, Page CD, Li L. Prion disease diagnosis by proteomic profiling. J Proteome Res. 2009 Feb;8(2):1030-6.

71. Dorey A, Tholance Y, Vighetto A, Perret-Liaudet A, Lachman I, Krolak-Salmon P, et al. Association of cerebrospinal fluid prion protein levels and the distinction between Alzheimer disease and Creutzfeldt-Jakob disease. JAMA Neurol. 2015 Mar;72(3):267-75.

72. Vallabh SM, Minikel EV, Williams VJ, Carlyle BC, McManus AJ, Wennick CD, et al. Cerebrospinal fluid and plasma biomarkers in individuals at risk for genetic prion disease. BMC Med. 2020 Jun;18(1):140.

73. Rhoads DD, Wrona A, Foutz A, Blevins J, Glisic K, Person M, et al. Diagnosis of prion diseases by RT-QuIC results in improved surveillance. Neurology. 2020 Aug;95(8):e1017-26.

74. Connor A, Wang H, Appleby BS, Rhoads DD. Clinical Laboratory Tests Used To Aid in Diagnosis of Human 
Prion Disease. J Clin Microbiol. 2019 Oct;57(10).

75. Atarashi R, Satoh K, Sano K, Fuse T, Yamaguchi N, Ishibashi D, et al. Ultrasensitive human prion detection in cerebrospinal fluid by real-time quaking-induced conversion. Nat Med. 2011 Feb;17(2):175-8.

76. Foutz A, Appleby BS, Hamlin C, Liu X, Yang S, Cohen Y, et al. Diagnostic and prognostic value of human prion detection in cerebrospinal fluid. Ann Neurol. 2017 Jan;81(1):79-92.

77. Sano K, Satoh K, Atarashi R, Takashima H, Iwasaki Y, Yoshida M, et al. Early detection of abnormal prion protein in genetic human prion diseases now possible using real-time QUIC assay. PLoS One. 2013;8(1):e54915.

78. Piconi G, Peden AH, Barria MA, Green AJE. Epitope mapping of the protease resistant products of RT-QuIC does not allow the discrimination of sCJD subtypes. PLoS One. 2019;14(6):e0218509.

79. Llorens F, Kruse N, Karch A, Schmitz M, Zafar S, Gotzmann N, et al. Validation of $\alpha$-Synuclein as a CSF Biomarker for Sporadic Creutzfeldt-Jakob Disease. Mol Neurobiol. 2018 Mar;55(3):2249-57.

80. Orrù CD, Groveman BR, Hughson AG, Manca M, Raymond LD, Raymond GJ, et al. RT-QuIC Assays for Prion Disease Detection and Diagnostics. Methods Mol Biol. 2017;1658:185-203.

81. Zerr I, Villar-Piqué A, Hermann P, Schmitz M, Varges D, Ferrer I, et al. Diagnostic and prognostic value of plasma neurofilament light and total-tau in sporadic Creutzfeldt-Jakob disease. Alzheimers Res Ther. 2021 Apr;13(1):86.

82. Steinacker P, Blennow K, Halbgebauer S, Shi S, Ruf V, Oeckl P, et al. Neurofilaments in blood and CSF for diagnosis and prediction of onset in Creutzfeldt-Jakob disease. Sci Rep. 2016 Dec;6:38737.

83. Abu-Rumeileh S, Baiardi S, Ladogana A, Zenesini C, Bartoletti-Stella A, Poleggi A, et al. Comparison between plasma and cerebrospinal fluid biomarkers for the early diagnosis and association with survival in prion disease. J Neurol Neurosurg Psychiatry. 2020 Nov;91(11):1181-8.

84. Thompson AGB, Luk C, Heslegrave AJ, Zetterberg H, Mead SH, Collinge J, et al. Neurofilament light chain and tau concentrations are markedly increased in the serum of patients with sporadic Creutzfeldt-Jakob disease, and tau correlates with rate of disease progression. J Neurol Neurosurg Psychiatry. 2018 Sep;89(9):955-61.

85. Noguchi-Shinohara M, Hamaguchi T, Nozaki I, Sakai K, Yamada M. Serum tau protein as a marker for the diagnosis of Creutzfeldt-Jakob disease. J Neurol. 2011 Aug;258(8):1464-8.

86. Villar-Piqué A, Schmitz M, Hermann P, Goebel S, Bunck T, Varges D, et al. Plasma YKL-40 in the spectrum of neurodegenerative dementia. J Neuroinflammation. 2019 Jul;16(1):145.

87. Norsworthy PJ, Thompson AGB, Mok TH, Guntoro F, Dabin LC, Nihat A, et al. A blood miRNA signature 
associates with sporadic Creutzfeldt-Jakob disease diagnosis. Nat Commun. 2020 Aug;11(1):3960.

88. Llorens F, Villar-Piqué A, Schmitz M, Diaz-Lucena D, Wohlhage M, Hermann P, et al. Plasma total prion protein as a potential biomarker for neurodegenerative dementia: diagnostic accuracy in the spectrum of prion diseases. Neuropathol Appl Neurobiol. 2020 Apr;46(3):240-54.

89. Behaeghe O, Mangelschots E, De Vil B, Cras P. A systematic review comparing the diagnostic value of 14-3-3 protein in the cerebrospinal fluid, RT-QuIC and RT-QuIC on nasal brushing in sporadic Creutzfeldt-Jakob disease. Acta Neurol Belg. 2018 Sep;118(3):395-403. 